\title{
OFICINA DE REUTILIZAÇÃO DE MATERIAIS: EDUCAÇÃO AMBIENTAL CRÍTICA NA FORMAÇÃO DE PROFESSORES
}

\author{
Letícia Aparecida Oliveira ${ }^{1}$
}

André Maciel da Silva ${ }^{2}$

Antonio Fernandes Nascimento Junior ${ }^{3}$

\begin{abstract}
RESUMO
O presente trabalho visa apresentar uma proposta de oficina pedagógica de educação ambiental, focada na reutilização de materiais e que estimule aos participantes uma abordagem crítica do tema. A oficina consiste, inicialmente, de discussões acerca dos problemas ambientais relacionados à produção e descarte indevido de lixo, além do consumismo, bem como sua ligação com a superprodução de lixo. A discussão busca tratar ainda, dos impactos causados pelo lixo à vida das pessoas, sejam eles diretamente ligados aos seres humanos, à saúde pública, à biodiversidade ou até mesmo às relações que os seres humanos tem com a natureza em geral, principalmente no que diz respeito às interações com o ambiente e os recursos naturais como um todo. Para subsidiar as discussões, os mediadores exibiram imagens que mostravam o descarte desenfreado de lixo e um pequeno vídeo que trata dos processos pelos quais os produtos passam durante o ciclo de produção. A atividade contou ainda com a elaboração de dois teatros de fantoches, produzidos através de materiais reutilizáveis. A atividade ocorreu durante a "Semana dos Museus", realizada no Museu de História Natural (MHN) da Universidade Federal de Lavras, MG (UFLA). Os resultados obtidos indicam a importância da prática no ensino de educação ambiental, uma vez que, segundo os relatos recolhidos ao final da atividade, a mesma foi prazerosa, dinâmica e ao mesmo tempo produtiva e motivadora, por ter proporcionado aos participantes o exercício da visão crítica sobre a educação ambiental de uma forma mais agradável e dinâmica.
\end{abstract}

PALAVRAS-CHAVE: Educação ambiental crítica. Reutilização de materiais. Formação de professores.

\footnotetext{
1 Graduanda em Ciências Biológicas (Licenciatura), Universidade Federal de Lavras, MG. leticiakittymg@hotmail.com

${ }^{2}$ Graduando em Ciências Biológicas (Licenciatura), Universidade Federal de Lavras, MG. andremaciel_29@hotmail.com

${ }^{3}$ Professor Adjunto do Departamento de Biologia, Universidade Federal de Lavras, MG. toni_nascimento@yahoo.com.br
} 


\title{
WORKSHOP OF REUTILIZATION OF MATERIALS: CRITICAL ENVIRONMENTAL EDUCATION IN TEACHER FORMATION
}

\begin{abstract}
This paper presents a proposal for a workshop for teaching environmental education focused on reuse of materials and encourages participants a critical approach to the subject. The workshop consists initially of discussions about environmental issues related to production and improper disposal of waste, as well as consumerism and its connection with the overproduction of trash. The discussion also aims to address impacts caused by waste in people's lives, whether directly related to humans, public health, biodiversity or even the relationship that humans have with nature in general, especially with regard to interactions with the environment and natural resources as a whole. To support the discussion, the mediators presented photos showing the rampant waste disposal and a short video that deals with the processes by which the products pass during the production cycle. The activity also included the development of two puppet theaters, produced with reusable materials. The activity took place during the "Semana dos Museus", held at the Museum of Natural History (MNH) of the Federal University of Lavras (UFLA). The results indicate the importance of practice in teaching environmental education, since, according to the reports collected at the end of the activity, it was enjoyable, dynamic, productive and motivating for giving participants the exercise of critical insight environmental education a more enjoyable and dynamic way.
\end{abstract}

KEY-WORDS: Critical environmental education. Reutilization of materials. Teacher formation.

\section{TALLER PARA LA REUTILIZACIÓN DE MATERIALES: EDUCACIÓN AMBIENTAL CRÍTICA EN LA FORMACIÓN PEDAGÓGICA}

\begin{abstract}
RESUMEN
En este trabajo se presenta una propuesta de taller para la enseñanza de educación ambiental centrado en la reutilización de materiales y alienta a los participantes una aproximación crítica al tema. El taller consiste inicialmente en las discusiones acerca de las cuestiones ambientales relacionadas con la producción y la eliminación inadecuada de residuos, más allá del consumismo y su relación con la producción excesiva de basura. El debate también se trata de abordar, los impactos causados por los residuos a la vida de las personas, ya sea directamente relacionados con los seres humanos, la salud pública, la biodiversidad o incluso la relación que los seres humanos tienen con la naturaleza en general, sobre todo en respecto a las interacciones con el medio ambiente y los recursos naturales en su conjunto. Para apoyar las discusiones, los mediadores exhibieron imágenes que muestran la rampante eliminación de residuos y un breve vídeo que se ocupa de los procesos por los que pasan los productos durante el ciclo de producción. La actividad también incluye el desarrollo de dos teatros de marionetas, elaborado con materiales reutilizables. La actividad se llevó a cabo durante el "Semana de los Museos", que tuvo lugar en el Museo de Historia Natural (MHN), de la Universidad Federal de Lavras - MG (UFLA). Los resultados indican la importancia de la práctica en la enseñanza de la educación ambiental, ya que, según los informes recogidos al final de la actividad, que era agradable, dinámico, productivo y motivador a la vez, proporcionando a los participantes el ejercicio de visión crítica de la educación ambiental de una manera más agradable y dinámico.
\end{abstract}


PALABRAS-CLAVE: Educación ambiental crítica. Reutilización de materiales. Formación pedagógica.

\section{INTRODUÇÃO E OBJETIVOS}

Atualmente um dos principais agravantes das questões ambientais é o consumo exagerado, onde o sentimento de consumir mais do que é preciso, torna-se cada vez mais presente na vida das pessoas. Assim, resulta na alta produção de lixo e a má utilização dos recursos naturais, o que gera impactos no meio ambiente e consequentemente na sociedade. Gonçalves et al. (2013), discorre sobre esta questão, afirmando que os problemas ambientais são agravados pelo consumismo, a grande produção de lixo e o descarte incorreto de materiais, podendo interferir no meio ambiente e afetar a biodiversidade. Dessa maneira, é possível perceber a importância de se compartilhar essas informações, principalmente através do desenvolvimento de atividades lúdicas para o ensino de educação ambiental, como por exemplo, oficinas pedagógicas. Segundo Obara et al. (2005), a utilização de oficinas pedagógicas tem capacidade de estimular uma reflexão crítica e problematizadora, fornecendo uma percepção acerca da educação ambiental de modo a reorienta-la. Sobre as oficinas que tem como objetivo oferecer um debate sobre a Educação Ambiental, seja esse debate técnico, metodológico, político ou filosófico, Xavier (2008) diz que é preciso trabalhar uma perspectiva biológica, geográfica, histórica, econômica e social, antes de compreender de fato os problemas ambientais e as oficinas pedagógicas são o ambiente ideal para essas discussões. Cruz et al. (2011) ressalta a importância das oficinas pedagógicas no processo educacional, por permitir processos dinâmicos de ensino e aprendizagem e consequentemente uma adequação à realidade dos processos. Dessa maneira, é possível utilizar materiais de baixo custo, como as embalagens descartadas pela sociedade, na construção do conhecimento pretendido de uma maneira dinâmica e que perpasse por várias áreas de conhecimento.

Nessa perspectiva, o objetivo deste trabalho foi a elaboração e execução de uma oficina pedagógica de educação ambiental como prática que busca despertar 
uma visão crítica e reflexiva sobre a educação ambiental a partir da reutilização de materiais, tomando como referência as questões agravantes da temática ambiental.

\section{DESENVOLVIMENTO}

A atividade foi desenvolvida pelos bolsistas do Programa Institucional de Bolsas de Iniciação à Docência (PIBID) de Biologia da Universidade Federal de Lavras - MG (UFLA) e foi realizada no Museu de História Natural (MHN) da referida universidade. A prática foi aberta aos alunos da UFLA, aos membros do PIBID de Biologia e aos professores supervisores do mesmo. A prática contou com a presença de 14 participantes e foi dividida em 4 etapas: Contextualização e problematização do tema, construção do teatro, apresentação do teatro e avaliação da prática.

\section{Primeira etapa: Contextualização e problematização do tema}

Inicialmente foram contextualizadas e problematizadas questões ambientais, tendo como ponto de partida aquelas relacionadas ao consumismo e como este pode estar diretamente associado à superprodução de lixo. Foi levantado com os participantes da oficina que o lixo traz danos diretos ou indiretos à vida das pessoas, causando poluição, danos à saúde pública e afetando a biodiversidade, além do próprio ser humano em todas as suas interações com o ambiente e os recursos naturais como um todo.

$\mathrm{Na}$ sequência, foi exibido um curta metragem intitulado "A História das Coisas", com duração aproximada de 21 minutos, versão brasileira do documentário "The Story of Stuff", de Annie Leonard, seguido de uma discussão sobre o tema tratado. O vídeo fala, basicamente, do processo de extração, produção e venda de produtos, focando no consumismo e no descarte de materiais, além da maneira com que todos os produtos que consumimos afetam comunidades em diversos países do mundo, a maior parte deles longe de nossos olhos.

Finalizando esta etapa foi exibida uma apresentação de slides, contendo, em um primeiro momento, fotos de diversos locais da cidade de Lavras-MG, destacando 
a superprodução e descarte de lixo nas ruas. À medida que eram projetadas as imagens os participantes relatavam por escrito suas percepções sobre as mesmas. Já em um segundo momento foram expostas imagens referentes à reutilização do lixo, uma das alternativas para o destino do lixo. À medida que as imagens eram exibidas ocorriam discussões sobre a produção e descarte do lixo e as possíveis alternativas para minimizar os problemas causados pelo mesmo.

\section{Segunda etapa: construção do teatro}

Nesta etapa foi proposto que os participantes elaborassem um teatro de fantoches à partir das discussões feitas. Os fantoches deveriam ser construídos através da reutilização de materiais disponibilizados pelos organizadores. Nessa etapa os participantes foram divididos em dois grupos de sete participantes.

Os materiais disponibilizados aos participantes, foram embalagens descartáveis continuamente produzidas pela população, que podem ser reutilizadas. Dentre os materiais estavam garrafas pet, latinhas de refrigerante, caixas de leite, potes de diversos tamanhos, palito de dente, palito de churrasco, rolo de papel higiênico, tampa de garrafa, embrulho de presente e papelão. Como complemento para a finalização dos fantoches e construção do cenário, além dos materiais citados, foram disponibilizados: tecidos de várias cores, Etil Vinil Acetato (E.V.A) de cores variadas, tinta para tecido, tinta guaxe, cola branca, cola quente, tesouras, papel crepom colorido e canetinhas coloridas.

Os participantes demonstraram bastante criatividade, frente à atividade proposta, e domínio sobre o tema. Foram elaborados fantoches de animais, referentes a problemas que o lixo causa à biodiversidade e à relação fauna/flora, fantoches de indústrias, representando a poluição, descarte de materiais em rios e também foram construídos fantoches de pessoas, representando certa culpa que os seres humanos têm sobre os problemas ambientais.

\section{Terceira etapa: apresentação dos teatros}


Foram apresentados dois teatros, representando a poluição causada pelas indústrias e pela população de um modo geral.

\section{Teatro 1}

Era uma vez um lindo lugar que toda manhã nascia um lindo sol. Neste local havia um rio, onde vários peixes nadavam felizes. Porém um dia chegou uma grande indústria.

Peixe: "Tá" na água?

Todos: "Tô"!

Peixe 1: "Tá" poluída?

Todos: Sim!

Todos: Olha, olha, olha a água com metal, água com metal, se "tu" nadar, "tu" não vai ficar legal. *música*

Peixe 2: Nooooooooooooossa. Cara, ultimamente "tô" me sentindo muito estranho. Eu era um peixe saudável, legal, bonito e agora "tô" me sentindo meio amarelo, verde, vermelho, "tô" mudando de cor. Tá muito estranho esse negócio. Não tá dando pra respirar.

*Peixe 2 morre. *

Tartaruga: Meu Deus o que aconteceu com nosso amigo? Vocês ainda estão lamentando a morte do nosso amigo peixinho?

Todos: Siiiiiiiiim.

Tartaruga: Vocês acham que tem alguma coisa a ver com essa fábrica que joga essa água preta em cima da gente?

Todos: Com certeza!

Jacaré: Até eu que sou um grande predador estou sofrendo. "Tô" sem alimento. Nem a opção de virar vegetariano eu tenho, até mesmo as plantinhas estão morrendo.

Tartaruga: Sem contar esse bando de lixo que eu ando comendo por ai.

Cobra Cascavel: Vocês pensam que é só o ambiente aquático que está sofrendo com isso? Eles destruíram todo o meu habitat.

Barata: E olhe para mim, querido. Estou quase morrendo. Não consigo mais viver nesse ambiente. Preciso de água limpa. Vou ter que migrar daqui.

Todos: Ai, ai, ai, ai. Tá chegando a hora. O rio tá poluído meu bem, eu tenho que ir embora.

*música*

Grande indústria: Uhuuuuu! Grandes lucros pra mim!!! 


\section{Teatro 2}

Gnomo da verdade: Ai oh! Lembra daquele filme da Xuxa que ela passa um maracujá na cara?

"Massa, né?"

Dona Ana: Lembro, eu quero aquilo pra mim também!

Gnomo da verdade: $E$ aquela hora que aquela mulher ficou presa na privada "véi"...

Dona Ana: HAHAHA. Morri de rir.

Gnomo da verdade: "Ow", dá um salgadinho ai! Mó larica.

*Dona Ana joga o saquinho no rio*

Gnomo da verdade: Ei! Joga a "bagaça" no rio não "uai". Que isso! Tá cheio de coisa ali.

Dona Ana: Mas foi só um papelzinho.

Gnomo da verdade: Só um papelzinho não. A gente não pode jogar as coisas no rio não "uai".

Tem dessa não. Tem que cuidar do rio. A gente depende do rio "uai". Que isso "cara".

Dona Ana: Mas, eu não fiz nada de mais.

Gnomo da verdade: Olha lá! Os peixes estão todos bravos com você.

*Dona onça entra no cenário*

Dona Ana: Oi dona onça!

Dona Onça: Olá, tudo bem? Acho que vou fazer uma boquinha, esse rio tá tão gostoso. Olha aquele peixão ali, ele mesmo que vou pegar.

*Onça se alimenta do peixe ${ }^{*}$ *

Gnomo da verdade: Olha ali. O peixe que sobrou tá brigando com você.

*Peixe 2 fica bravo com a Dona Ana*

Dona Ana: Mas eu não entendo por que ele está brigando, eu não fiz nada demais.

Gnomo da verdade: Fez sim! Jogou o lixo ai. Fala ai peixe pra ela.

*Peixe 2 continua bravo com a Dona Ana*

Gnomo da verdade: Ai! Ele tá falando que você é uma irresponsável.

Dona Ana: Desculpa.

Gnomo da verdade: Você não pode fazer essas coisas. Tá fazendo mal pra sociedade "cara".

Dona Ana: Foi só um papelzinho.

Gnomo da verdade: Mas não pode!

*Aparece o monstro do lixo*

Monstro do lixo: MUAHAHAHAHAHAHA! Mal sabe Ana que com esse papelzinho, juntamente com o que as indústrias e todo mundo joga nesse rio, eu, o bicho da poluição, cresço, cresço, fico gordo e bonito. HAHAHAHAHAHA.

Gnomo da verdade: Ai Ana, olha só. O bicho vai te pegar em "cara". Ele tá só crescendo.

Dona Ana: Mas e agora, o que eu faço pra melhorar isso?

*Aparece o capitão conscientização.*

Capitão Conscientização: Pela união de seus poderes. Eu sou...

Todos: O Capitão Planeta!!!! 
Capitão Conscientização: Só que não! Capitão Planeta é uma ova. Ele já morreu faz tempo. Meu nome é Capitão Conscientização. Enfim, Dona Ana. Você acha bonito jogar lixo no rio? Jogar lixo nas ruas?

Dona Ana: Mas foi só um papelzinho!

Capitão Conscientização: Não foi só um papelzinho! Para você pode ser apenas um papelzinho. Mas se cada um jogar um papelzinho, vai juntar um monte de lixo e o bicho da poluição vai só crescer.

Dona Onça: Nossa! Nem tenho mais vontade de me alimentar. Como vou fazer para me reproduzir pessoal? Ana, você precisa entender que tudo isso é um ciclo. Na natureza a vida funciona mais ou menos assim. Um animal se alimenta do outro. Eu, me alimento de peixes e se você continuar poluindo o rio, eu vou precisar procurar outro lugar para me reproduzir.

Dona Ana: Eu vou mudar, vou melhorar.

Gnomo da verdade: Tomara mesmo!

Capitão Conscientização: Então digo para vocês e para toda plateia...

Todos: O poder é de vocês!!!

\section{Quarta etapa: avaliação}

Para finalizar, os participantes da oficina avaliaram a atividade. Para manter sigilo, serão identificados pela letra $P$ (participante).

P1: "A atividade foi muito interessante e contribuiu para uma visão mais crítica em relação ao processo de produção e descarte das embalagens, proporcionando uma reflexão sobre como tem sido minha atuação neste processo. Assim, o vídeo, teatro e discussão proporcionaram uma outra visão da reutilização de materiais de forma mais criativa e motivadora".

P2: "A atividade foi bastante proveitosa. O despertar de consciência com o vídeo, as imagens e as fotos foram efetivas para mim. O teatro de reutilização, além de já ser um passo para os 5 R's, foi muito pedagógico e reafirmou a necessidade de ações concretas para a educação ambiental. Além disso, através da oficina pude perceber que o consumo exagerado tem grande influência nas questões ambientais, principalmente aquelas relacionadas ao descarte de lixo.".

P3: "Acredito que o minicurso cumpriu seu papel, sendo um espaço de debate sobre a educação ambiental e a reutilização de materiais, além da parte da oficina 
estimular nossa criatividade. A discussão das fotos também foi muito interessante, contextualizando o curso à cidade que estamos inseridos e a culpa que nós temos como indivíduos que vivem no local.".

P4: "A oficina foi incrível, uniu diversão, problematização, discussão, aguçou a criatividade e nos colocou a par de como realmente o capitalismo e o consumismo estão diretamente ligados com a produção excessiva de lixo, de forma bastante clara. Além disso, contribuiu para que nós enxergássemos que grande parte dos problemas ambientais são causados por nossas ações, seja direta ou indiretamente. ".

P5: "Uma atividade produtiva e dinâmica. Adorei a proposta do vídeo, que possibilitou o levantamento de questões e elementos que contribuíram para a discussão inicial. Avalio a metodologia do uso das fotos/imagem positivamente, casada com a proposta de socialização das observações, que geraram um debate interativo e rico. Acredito que oficinas como essa deveriam ser desenvolvidas em toda a cidade, principalmente nas escolas, para que as crianças entendam desde cedo que, muitas vezes, os seres humanos são os culpados pela poluição. ".

P6: "A atividade possibilitou uma reflexão sobre os processos em que as coisas passam antes de chegar até nós, bem como seu destino final, o lixo, que muitas vezes é depositado em locais inapropriados. Neste sentido, uma educação ambiental crítica é o principal caminho. As pessoas deveriam ter essas mesmas informações, para repensar nos seus atos, percebendo que a culpa da poluição e demais problemas ambientais também é dela.".

\section{DISCUSSÃO}

A base para a avaliação da atividade foi o discurso dos participantes sobre a prática realizada, que foi filmado e posteriormente analisado. Nesse sentido, avaliando o discurso dos participantes, foi possível ressaltar algumas questões.

Tendo como base a avaliação dos participantes, pôde-se perceber que a oficina cumpriu seu papel de instigar a consciência crítica acerca da educação ambiental, fazendo com que os participantes se enxerguem como parte do ambiente e agente transformador do mesmo, despertando assim maior respeito pela questão 
ambiental. Essa afirmação é sustentada por todos os relatos, nos quais os participantes afirmam que a culpa de todos ou parte dos problemas ambientais é do ser humano. Dessa maneira, como é possível perceber nos relatos, o ser humano deve repensar em seus atos, de modo a evitar ou diminuir os impactos ambientais presentes na sociedade atual. Tal afirmação tem ampla relação com o Tema Transversal Meio Ambiente, descrito nos Parâmetros Curriculares Nacionais. Segundo o PCN-Temas transversais (1998), perceber-se integrante e agente transformador do ambiente, identificando seus elementos e as interações entre eles, contribui ativamente para a melhoria do meio ambiente.

Também foi possível perceber por meio das avaliações P2 e P4 que o atual sistema econômico tem grande influência sobre a necessidade de consumo da população e consequentemente sobre as questões ambientais. Assim, podemos perceber que a educação ambiental não é apenas uma questão ecológica, mas também social. Segundo Silva e Calixto (2013), na sociedade atual percebe-se que a interação da sociedade com o ambiente tem sido conflituosa e os aspectos econômicos tem se sobreposto a qualidade de vida coletiva.

É possível ainda perceber que, segundo a avaliação P5, as discussões e o conhecimento adquirido na oficina devem ser levados adiante, às futuras gerações, principalmente às escolas. Essa afirmação é fundamentada por Santos (2007), que salienta a importância da conscientização para a conservação e defesa do meio ambiente. Defende ainda a necessidade de que essa conscientização se alastre para as futuras gerações.

Sobre a oficina, de um modo geral, é possível perceber através dos relatos que a mesma cumpriu seu papel ao oferecer um espaço para discussão sobre as questões ambientais, uma vez que as oficinas com caráter reflexivo, podem se tornar fontes de conhecimento, estimulando a reflexão, questionamentos e conscientização das pessoas. Segundo Buogo (2005), as oficinas pedagógicas são um importante ambiente que permite essas reflexões, possibilitando a construção do conhecimento pelos participantes. 


\section{CONCLUSÃO}

Os relatos dos participantes mostraram que a atividade foi importante na construção da consciência crítica da Educação Ambiental, despertando a noção de que o ser humano pertence ao meio ambiente e atua diretamente na sua transformação.

Além disso, pôde-se perceber que a utilização de oficinas como método de ensino de educação ambiental mostrou-se uma ferramenta válida para a abordagem de questões ambientais, principalmente no que diz respeito a reutilização de materiais, uma vez que foi eficiente em trazer aos participantes reflexões e discussões sobre os problemas ambientais causados pelo consumismo e excesso de produção de lixo. Consequentemente, tornou possível o despertar de uma visão crítica e ao mesmo tempo reflexiva sobre as práticas cotidianas da sociedade atual e como lidar com essas situações. Pôde-se perceber ainda que a atividade possibilitou resultados significativos, uma vez que os próprios participantes trouxeram contribuições acerca dos conceitos abordados, tornando a atividade mais dinâmica e produtiva.

Tendo como base essas considerações, foi possível notar que a atividade cumpriu seu papel, uma vez que os objetivos da proposta foram atingidos.

\section{REFERÊNCIAS}

BRASIL. Ministério de Educação. Parâmetros Curriculares Nacionais: terceiro e quarto ciclos: Temas Transversais. Secretaria de Ensino Fundamental. Brasília: MEC/SEF, 1998.

BUOGO, A. L; COSTA, A.E; STEDILE, N. L. R; MATTANA, S.M.D. Oficinas pedagógicas: experiências para qualificar a ação docente. In: Anais do IV Encontro Ibero-Americano de Coletivos Escolares e Redes de Professores que Fazem Investigação na sua Escola, 2005.

CRUZ, V.R.M; ANTUNES, A.M; FARIA, J. C. N de M. Oficina de produção de materiais pedagógicos e lúdicos com Reutilizáveis: uma proposta de educação ambiental no ensino de Ciências e biologia. Enciclopédia Biosfera, Centro Científico Conhecer - Goiânia, vol.7, N.12; 2011 Pág. 1.

GONÇALVES, L. V.; OLIVEIRA, L. A.; SILVA, A. M.; SILVA, J. C. F.; NASCIMENTO JUNIOR, A. F. Oficina de reutilização de materiais como prática pedagógica de educação ambiental crítica na 
formação de professores de ciências e biologia. Revista Práxis, Volta Redonda, v. especial, p. 297302, 2013.

OBARA, A.T; SILVEIRA, M. P.; KIOURANIS, N. M. M. Oficinas de educação ambiental: desafios da prática problematizadora. Enseñanza De Las Ciencias, 2005. NÚMERO EXTRA. VII CONGRESO.

SANTOS, E. T. A. Educação ambiental na escola: conscientização da necessidade de proteção da camada de ozônio. Monografia de pós-graduação. Universidade Federal de Santa Maria - Santa Maria. 96p. 2007.

SILVA, E. L.; CALIXTO, P.M. Educação ambiental na escola: curso de formação para professores. VI Mostra Nacional de Iniciação Científica e Tecnológica Interdisciplinar. Camboriú, 2013.

XAVIER, M. A. Oficinas de Educação Ambiental: contribuição à educação continuada dos professores do município de Luis Eduardo Magalhães - Bahia. 2008. $51 \mathrm{f}$. Trabalho de Conclusão de Curso (Especialização em Educação Ambiental) - Serviço Nacional de Aprendizagem Comercial, Brasília, 2008. 